\title{
Temperature Effect on Frictional Force when an Acrylic Fiber is Pulled out of Parallel Fiber Bundles
}

\author{
Tooru Nogai, Motozoo Ihara and Yutaka Narumi*, Members, TMSJ \\ Faculty of Engineering, Shizuoka University, Hamamatsu, Shizuoka Pref.
}

Based on the Journal of the Textile Machinery Society of Japan, Transactions, Vol. 30, No. 7, T119-T124 (1977)

\begin{abstract}
Experiments were made in the temperature range from 20 to $100^{\circ} \mathrm{C}$ to determine the frictional force acting on an acrylic filament pulled out from paralleled fiber bundles of cotton, viscose rayon, or polyester fibers, and following results were obtained:

(1) The temperature influence on the frictional force varies according to the kinds of fibers. The friction when pulled out from cotton fiber bundles has the minimum at $80^{\circ} \mathrm{C}$, while that from viscose rayon or polyester fiber bundles reaches the maximum at $80^{\circ} \mathrm{C}$.

(2) The pulling out frictional force from fiber bundles, $f_{s}(\mathrm{~g} / \mathrm{cm})$, is expressed by the equation:

$$
f_{s}=K_{0} P^{\alpha}
$$

where $P\left(\mathrm{~g} / \mathrm{cm}^{2}\right)$ is the external force applied on parallel fiber bundles, $K_{0}$ and $\alpha$ are experimental constants affected by the kinds of fibers, temperature, and compressive properties of fiber bundles.
\end{abstract}

\section{Introduction}

In our previous papers ${ }^{[1,2]}$, we measured the frictional force when fine metallic wires are drawn through parallel fiber bundles in the temperature range from $20^{\circ} \mathrm{C}$ to $130^{\circ} \mathrm{C}$, and obtained the following relation

$$
f=K(P / \sqrt{\xi})^{\beta}
$$

where $f$ is the frictional force $(\mathrm{g} / \mathrm{cm}), P$ the external pressure $\left(\mathrm{g} / \mathrm{cm}^{2}\right)$ applied on the bundle, $\xi$ the volumetric ratio of the bundle, $K$ and $\beta$ are experimental constants.

In this paper, we measure the frictional force when an acrylic filament is pulled out from parallel fiber bundles of cotton, viscose rayon, or polyester fibers by the same way as reported in the previous paper ${ }^{[2]}$, and try to confirm whether or not eq. (1) is applicable to an acrylic filament. It is another purpose of us to obtain an experimental equation concerning the frictional force when the compressive characteristic is considered.

\section{Experiment}

\subsection{Samples}

Samples are made from card slivers of cotton (mean diameter: $18 \mu \mathrm{m}$, mean fiber length: $30 \mathrm{~mm}$, fiber density: $\left.1.54 \mathrm{~g} / \mathrm{cm}^{3}\right)$, viscose rayon $\left(11 \mu \mathrm{m}, 44 \mathrm{~mm}, 1.51 \mathrm{~g} / \mathrm{cm}^{3}\right)$ and polyester fibers $\left(12 \mu \mathrm{m}, 38 \mathrm{~mm}, 1.38 \mathrm{~g} / \mathrm{cm}^{3}\right)$. After disentangling these slivers, we cut the slivers at the length $100 \mathrm{~mm}$ and put these in a rectangular channel (width: $40 \mathrm{~mm}$, length: $100 \mathrm{~mm}$, height: $50 \mathrm{~mm}$ ). The sample weighing $7 \mathrm{~g}$ in general and $3 \mathrm{~g}$ in case of polyester fibers is first divided into two halves, and one of them is put in the channel. Then an acrylic filament (mean fiber diameter: $14 \mu \mathrm{m}$ ) is put on the surface of the bundle, and then the remaining half is put in the channel.

In the case of viscose rayon and polyester fibers, such clean samples are used as the lubricants on which are removed by the same way as used in the previous paper ${ }^{[2]}$. 2.2 Experimental Apparatus and Procedure

The apparatus used in this study is the same as used in our previous study ${ }^{[2]}$.

The sample is stored in a oven kept at a constant temperature for $30 \mathrm{~min}$, and then the experiment is started to measure the frictional force at the temperature between 20 and $100^{\circ} \mathrm{C}$. The external pressure range is from 3.9 to $38.9 \mathrm{~g} / \mathrm{cm}^{2}$ in general, but from 1.9 to $19.3 \mathrm{~g} / \mathrm{cm}^{2}$ in case of polyester fibers.

The relation between the volumetric ratio $\xi$ in eq. (1) and the height of the parallel fiber bundle $h(\mathrm{~cm})$ is exressed by

$$
\xi=W(\rho A h)^{-1}
$$

\footnotetext{
* Present Address: Aichi Institute of Technology, Toyota, Aichi Pref.
} 
Table 1. Constants $C$ and $\delta$ in eq. (3)

\begin{tabular}{|c|c|c|c|c|c|c|c|c|c|c|}
\hline \multirow[t]{3}{*}{ Sample } & \multicolumn{2}{|l|}{ Cotton } & \multicolumn{4}{|c|}{ Viscose rayon fiber } & \multicolumn{4}{|c|}{ Polyester fiber } \\
\hline & \multirow[b]{2}{*}{$C$} & \multirow[b]{2}{*}{$\delta$} & \multicolumn{2}{|c|}{ non-cleaned } & \multicolumn{2}{|l|}{ cleaned } & \multicolumn{2}{|c|}{ non-cleaned } & \multirow{2}{*}{$\begin{array}{l}\text { cleaned } \\
C\end{array}$} & \multirow[b]{2}{*}{$\delta$} \\
\hline & & & $C$ & $\delta$ & C & $\delta$ & $C$ & $\delta$ & & \\
\hline $20^{\circ} \mathrm{C}$ & $1.2 \times 10^{-2}$ & 0.44 & $1.7 \times 10^{-2}$ & 0.42 & $2.0 \times 10^{-2}$ & 0.38 & $1.9 \times 10^{-2}$ & 0.46 & $1.8 \times 10^{-2}$ & 0.52 \\
\hline 40 & 1.2 & 0.44 & 1.9 & 0.42 & - & - & 1.9 & 0.47 & - & - \\
\hline 60 & 1.2 & 0.44 & 2.4 & 0.38 & 2.5 & 0.36 & 1.9 & 0.48 & 1.9 & 0.50 \\
\hline 80 & 1.2 & 0.44 & 2.8 & 0.34 & - & - & 2.1 & 0.49 & - & - \\
\hline 100 & 1.2 & 0.44 & 2.9 & 0.33 & 2.7 & 0.33 & 2.3 & 0.49 & 2.2 & 0.52 \\
\hline
\end{tabular}

where $W$ is the mass $(\mathrm{g})$ of the sample, $\rho$ the density $\left(\mathrm{g} / \mathrm{cm}^{3}\right)$, and $A$ the crosssectional area $\left(\mathrm{cm}^{2}\right)$ of the rectangular channel.

\section{Experimental Results and Discussions}

3.1 Relation between Volumetric Ratio and External Pressure

As in our previous paper ${ }^{[1,2]}$, the relation between $\xi$ and $P\left(\mathrm{~g} / \mathrm{cm}^{2}\right)$ is expressed by

$$
\xi=C P^{\delta}
$$

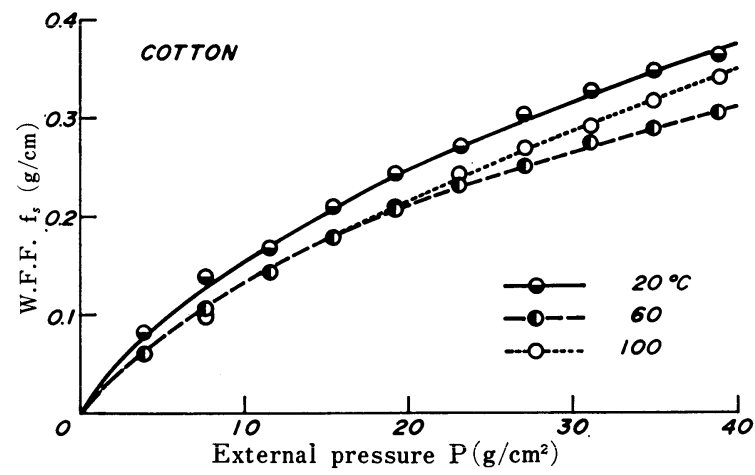

Fig. 1 Relation between pulling out frictional force and external pressure

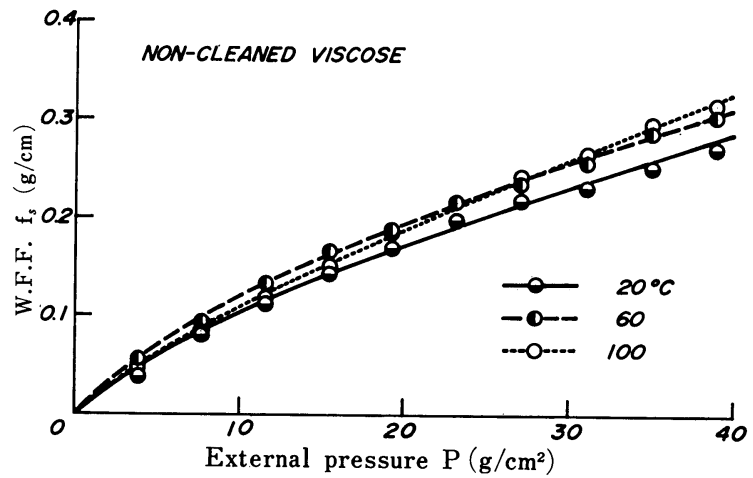

Fig. 2 Relation between pulling out frictional force and external pressure where $C$ and $\delta$ are experimental constants determined by the kind of fibers and the temperature, the numerical values of which are shown in Table 1.

The range of $\boldsymbol{P}$ in this study corresponds approximately to the low compression region reported in our previous paper $^{[5]}$ roughly from 2 to $30 \mathrm{~g} / \mathrm{cm}^{2}$. Compared with that region, the values of $C$ and $\delta$ in Table 1 are larger. It means that the bundles in this study are more easily compressed. It is thought that the deformation of fibers in the previous paper is more difficult than that of parallel fiber bundles in this study, because the arrangement of fibers in the previous paper is random. The change of $C$ and $\delta$ in this study by temperature rise is less than that in the previous paper. It is thought this is due to the difference of the sample structure and experimental conditions, namely the compression in this study is done in the rectangular channel, while in the previous study is done without the container.

\subsection{Frictional Force}

The frictional force (abbreviated as W.F.F. in figures) for cotton fibers and viscose rayon fibers measured is shown in Figs. 1 and 2. $f_{s}(\mathrm{~g} / \mathrm{cm})$ means the maximum static friction. Because the dynamic friction shows the same tendency as the static friction, only the case of the static friction is represented here.

From these figures, it is clear that $f_{s}$ increases with the increase of $P\left(\mathrm{~g} / \mathrm{cm}^{2}\right)$ concavely to the pressure axis. This almost agrees with the results for viscose rayon fiber bundles in the low pressure range obtained by S. Kinosita et al., and shows the same tendency as in our previous study for fine metallic wires ${ }^{[2]}$.

The influence of temperature on $f_{s}$ is shown in Fig. 3. $f_{s}$ of viscose rayon and polyester fibers increases with temperature rise and decreases when the temperature is over $80^{\circ} \mathrm{C}$. $f_{s}$ of cotton fibers decreases with temperature rise, and increases when the temperature is over $80^{\circ} \mathrm{C}$. This temperature $80^{\circ} \mathrm{C}$ at which the tendency of $f_{s}$ changes is near the glass transition temperature of acrylic fibers ${ }^{[4]}$. Even in the previous paper ${ }^{[1]}$, it is observed that the pulling out force changes abruptly at about that temperature when a fine metallic wire is pulled out from acrylic parallel fiber bundles. Therevore it is thought that the temperature 


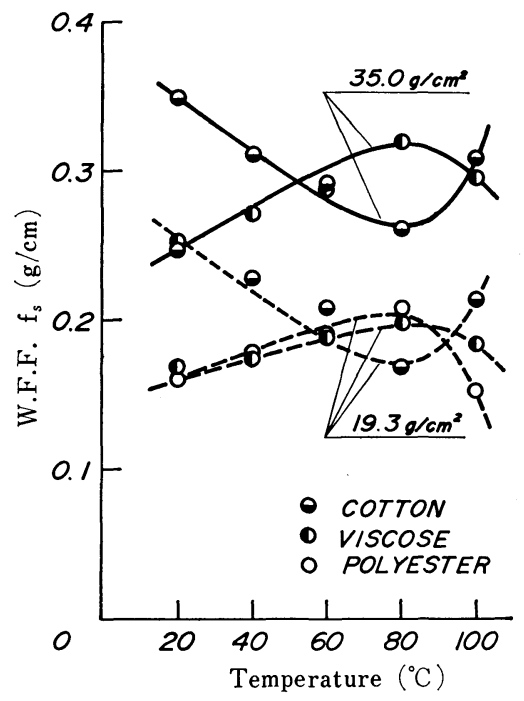

Fig. 3 Relation between pulling out frictional force and temperature

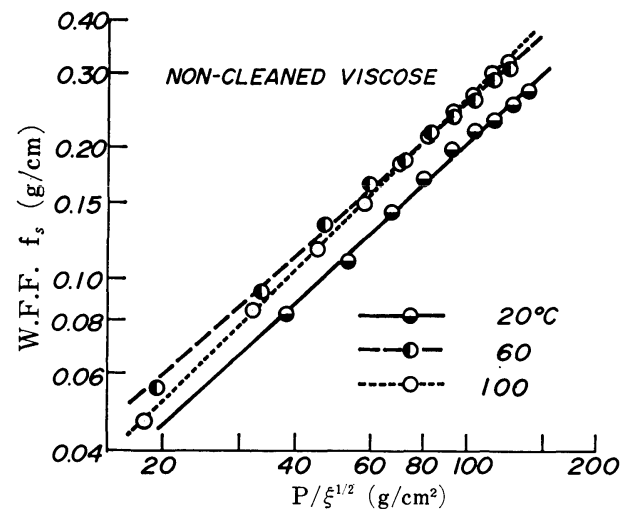

Fig. 4 Relation between pulling out frictional force and interfiber force parameter

dependency of $f_{s}$ is affected strongly by the property of the material pulled out.

The relation between $f_{s}$ and the inter-fiber parameter $P / \sqrt{\xi}\left(\mathrm{g} / \mathrm{cm}^{2}\right)^{[2]}$ is shown in Fig. 4. From this figure, eq. (1) is satisfied in the $P$ region treated in this study. The same tendency is obtained also in case of cotton and polyester fibers ${ }^{[8,9]}$. So, the measured results are substituted into eq. (1), and experimental constants $\beta$ and $K$ are obtained as shown in Table 2.

Unlike the previous papers ${ }^{[1,2]}, \beta$ varies with temperature similarly as $K$. But its tendency is different from $K$. Because the inter-fiber force parameter is determined by the compressive characteristic of each fiber bundle, it seems that the temperature dependency of $\beta$ and $K$ is different from that between $f_{s}$ and temperature.

As for cotton fibers, the temperature dependency of $\beta$ and $K$ agrees with that of $f_{s}$, because their compressive characteristic does not vary with temperature. However, as the compressive characteristics of viscose rayon and polyester fibers depend on temperature, the temperature dependency of $\beta$ and $K$ is a little different. $\beta$ of viscose rayon fibers has the same tendency as $f_{s}$, but their $K$ becomes concave to the temperature axis and has the maximum value at about $40^{\circ} \mathrm{C}$. $\beta$ of polyester fibers has the inverse tendency to $f_{s}$, and $K$ has the maximum value at about $60^{\circ} \mathrm{C}$. Because the temperature at which each fiber has the maximum value of $K$ agrees approximately with the glass transition temperature for each fiber composing the bundle, it is expected that $K$ is a parameter depending on the surface nature of materials used for friction. Contrary to this, $\beta$ seems to be a factor governing the mechanism of friction as mentioned in the previous paper, and is thought to depend on the property of the filament pulledout.

\subsection{Effect of Lubricants}

The relations between $f_{s}$ and $\boldsymbol{P}$ or the inter-fiber force parameter for cleaned viscose rayon fibers are shown in Figs. 5 and 6.

From Fig. $5, f_{s}$ seems to decrease a little with temperature rise. Compared with non-cleaned samples, the difference is large in the region at low temperature, and little in the region at high temperature. Samples of polyester fibers have a similar tendency in the region at low temperature.

From Fig. 6, eq. (1) seems to be satisfied also by cleaned samples of viscose rayon, fibers, and similarly by cleaned polyester samples. $\beta$ and $K$ are shown in Table 2 . These

Table 2. Constants $\beta$ and $K$ in eq. (1)

\begin{tabular}{clllllllllll}
\hline Sample & \multicolumn{1}{l}{ Cotton } & \multicolumn{4}{c}{ Viscose rayon fiber } & \multicolumn{4}{c}{ Polyester fiber } \\
\hline & & \multicolumn{4}{l}{ non-cleaned } & \multicolumn{2}{c}{ cleaned } & \multicolumn{2}{c}{ non-cleaned } & \multicolumn{2}{c}{ cleaned } \\
Temp. & $\beta$ & $K$ & $\beta$ & $K$ & $\beta$ & $K$ & $\beta$ & $K$ & $\beta$ & $K$ \\
\hline $20^{\circ} \mathrm{C}$ & 0.76 & $7.8 \times 10^{-3}$ & 0.75 & $5.6 \times 10^{-3}$ & 0.098 & $2.8 \times 10^{-3}$ & 0.90 & $3.4 \times 10^{-3}$ & 0.90 & $3.0 \times 10^{-3}$ \\
40 & 0.78 & 6.5 & 0.77 & 6.3 & - & - & 0.83 & 5.4 & - & - \\
60 & 0.84 & 4.5 & 0.88 & 4.4 & 0.98 & 3.0 & 0.80 & 6.6 & 0.89 & 4.0 \\
80 & 0.93 & 2.5 & 0.96 & 3.4 & - & - & 0.87 & 5.4 & - & - \\
100 & 0.92 & 3.3 & 0.97 & 3.0 & 0.91 & 3.8 & 0.95 & 2.9 & 0.97 & 3.5 \\
\hline
\end{tabular}




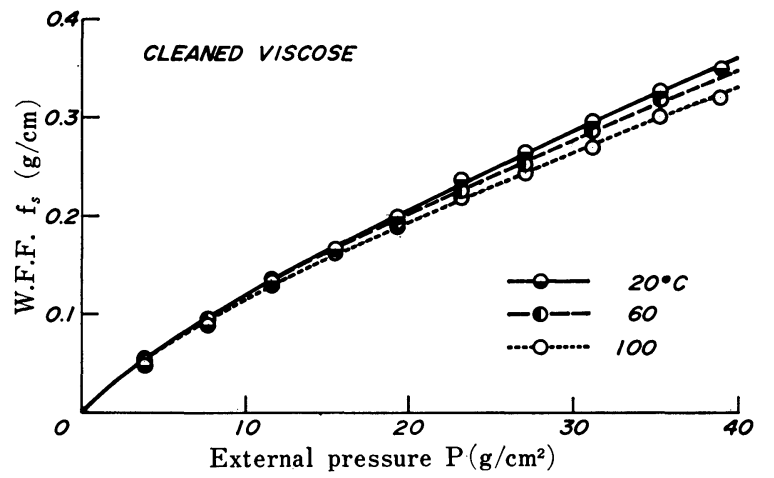

Fig. 5 Relation between pulling out frictional force and external pressure

values are different a little in case of non-cleaned samples.

As mentioned above, it is clear that the lublicant exerts influence upon the pulling-out friction.

In case of viscose fibers, the lublicant has low viscosity and is adhesive little because the most lublicant is animal ${ }^{[2]}$. So, the friction is in the state of boundary lublication. Therefore the frictional force decreases with increase of the lublicant viscosity, in other words, by lowering temperature. In case of polyester fibers, because antistatic agents are added to the lublicant in addition to slickners, the frictional behavior is in the state of hydrodynamic lublication rather than the boundary lublication. Therefore the frictional resistance increases with temperature rise.

\subsection{Discussion}

The relation between the surface frictional force $f_{d}$ and the external pressure for general high polymer solids is represented by the following expression based on the adhesion theory;

$$
f_{d}=a P^{n}
$$

where $a$ and $n$ are constants depending on the materials, and $n$ is the value from $(2 / 3)$ to 1.0 .

It is clarified that eq. (4) is also satisfied in case of the friction between staple fibers. For example, Mazur ${ }^{[10]}$ showed that, by measuring the fiber fiber friction of nylon

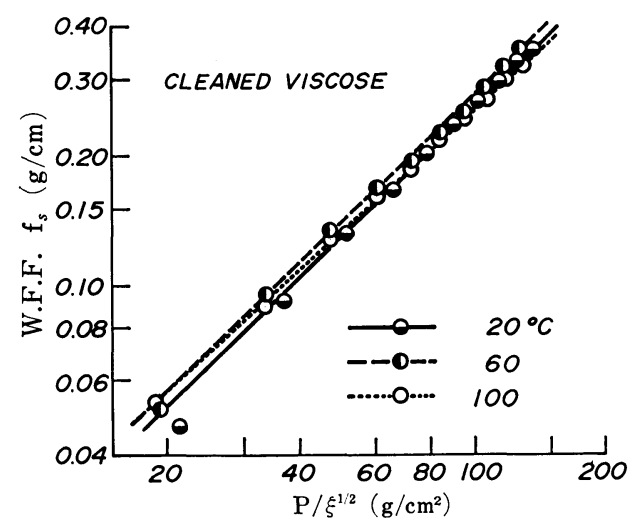

Fig. 6 Relation between pulling out frictional force and interfiber force parameter

and viscose rayon fibers, $n$ is between 0.80 and 0.94 . Okajima et al. ${ }^{[6]}$ showed that eq. (4) is satisfied in case of the fiber to metal friction of rabbit fibers. Lord ${ }^{[7]}$ showed that eq. (4) is satisfied in case of the friction between cotton boundles.

The relation between $f_{s}$ and $P$ is plotted on a logarithmic figure, by the data from Figs. 1 and 2, and a linear relation is obtained as follows:

$$
f_{s}=K_{0} P^{\alpha}
$$

$K_{0}$ and $\alpha$ calculated from experimental results are shown in Table 3. Eq. (5) is formally the same as eq. (4). Therefore the frictional mechanism is explained microscopically by the adhesion theory of general high polymer solids.

Substituting eq. (3) into eq. (1), and replacing $K_{0}$ and $\alpha$ with the following expressions

$$
\left.\begin{array}{l}
K_{0}=K C^{-(\beta / 2)} \\
\alpha=(1-\delta / 2) \beta
\end{array}\right\}
$$

eq. (1) becomes the same as eq. (5). Therefore it seems that eq. (1) expresses the frictional component and eq. (3) the compressive component of the pulling out frictional char-

\begin{tabular}{|c|c|c|c|c|c|c|c|c|c|c|}
\hline \multirow[b]{3}{*}{ Temp. } & \multicolumn{2}{|c|}{ Cotton } & \multicolumn{4}{|c|}{ Viscose rayon fiber } & \multicolumn{4}{|c|}{ Polyester fiber } \\
\hline & \multirow[b]{2}{*}{$\alpha$} & \multirow[b]{2}{*}{$K_{0}$} & \multicolumn{2}{|c|}{ non-cleaned } & \multicolumn{2}{|c|}{ cleaned } & \multicolumn{2}{|c|}{ non-cleaned } & \multicolumn{2}{|c|}{ cleaned } \\
\hline & & & $\alpha$ & $K_{0}$ & $\alpha$ & $K_{0}$ & $\alpha$ & $K_{0}$ & $\alpha$ & $K_{0}$ \\
\hline $20^{\circ} \mathrm{C}$ & 0.59 & $4.2 \times 10^{-2}$ & 0.59 & $2.6 \times 10^{-2}$ & 0.79 & $1.9 \times 10^{-2}$ & 0.69 & $2.0 \times 10^{-2}$ & 0.67 & $1.8 \times 10^{-2}$ \\
\hline 40 & 0.61 & 3.6 & 0.61 & 2.9 & - & - & 0.63 & 2.8 & - & - \\
\hline 60 & 0.66 & 2.9 & 0.71 & 2.3 & 0.80 & 1.8 & 0.63 & 3.2 & 0.67 & 2.3 \\
\hline 80 & 0.73 & 1.9 & 0.80 & 1.9 & - & - & 0.66 & 2.9 & - & - \\
\hline 100 & 0.72 & 2.5 & 0.81 & 1.6 & 0.76 & 2.0 & 0.72 & 1.8 & 0.73 & 2.2 \\
\hline
\end{tabular}
acteristic, respectively.

Table 3. Constants $\alpha$ and $K_{0}$ in eq. (5) 


\section{Conclusion}

We investigate experimentally the temperature dependency of the frictional characteristic when an acrylic filament is pulled out from parallel fiber bundles made of cotton, viscose rayon and polyester fibers, and the following results are obtained:

(1) The temperature influence on the frictional force varies according to the kinds of fibers. The frictional force when pulled out from cotton fiber bundles has the minimum value at $80^{\circ} \mathrm{C}$, while that from viscose rayon and polyester fiber bundles reaches the maximum at $80^{\circ} \mathrm{C}$.

(2) The pulling out frictional force $f \mathrm{~s}(\mathrm{~g} / \mathrm{cm})$ for each fiber is expressed by a power function of the inter-fiber force parameter $(P / \sqrt{\xi})$.

(3) Substituting the compressive characteristic of parallel fiber bundles to the inter-fiber force parameter, $f_{s}$ is denoted as a power function of the external pressure;

$$
f_{s}=K_{0} P^{\alpha}
$$

where $K_{0}$ and $\alpha$ are experimental constants. From this, it can be deduced that the pulling out friction is the aggregate of the fiber fiber frictional phenomena based on the adhesive theory.

(4) The effect of lublicant is large, and the temperature dependency of the frictional force varies with the viscosity and add-on of lublicant.

We thank to Hamamatsu members of Nisshin Spinning Co., Ltd., who offered slivers used in this study, and Messrs. H. Hattori, K. Mimura, T. Kimura and K. Mihara who carried on the experiments together with us.

\section{Literature Cited}

[1] T. Nogai, Y. Narumi; J. Text. Mach. Soc. Japan, 26, T84 (1973)

[2] T. Nogai, Y. Narumi, M. Ihara; ibid., 27, T65 (1974)

[3] S. Kinoshita, T. Takizawa; Sen-i Gakkaishi, 15, 455 (1959)

[4] Handbook of Fibers, Part of Materials, 251, Sen-i Gakkai (Maruzen)

[5] T. Nogai, Y. Narumi; J. Text. Mach. Soc. Japan, 25, T180 (1972)

[6] S. Okajima, S. Ikeda, T. Inoue; Sen-i Gakkaishi, 14, 400 (1958)

[7] E. Lord; J. Text. Inst., 46, P41 (1955)

[8] T. Nogai, Y. Narumi, M. Ihara; Print presented at the 29th Annual Meeting of the Text. Mach. Soc. Japan, 49 (1976)

[9] T. Nogai, Y. Narumi; Print presented at the 28th Annual Meeting of the Text. Mach. Soc. Japan, 39 (1975)

[10] J. Mazur; J. Text. Inst., 46, T712 (1955) 